\title{
A retrospective study in adult patients with septic shock and multiple organ failure demonstrated improved 28-day survival with adjunct TPE compared to standard care alone: true effect or mediated by a negative fluid balance achieved by RRT?
}

\author{
Patrick M. Honore*, Leonel Barreto Gutierrez, Luc Kugener, Sebastien Redant, Rachid Attou, Andrea Gallerani and \\ David De Bels
}

We read with great interest the recent article by Keith et al. who concluded that their retrospective, observational study in adult patients with septic shock and multiple organ failure demonstrated improved 28-day survival with adjunct therapeutic plasma exchange (TPE) compared to standard care alone [1]. The 28-day mortality rate was $40 \%$ in the TPE group (TPE+) versus $65 \%$ in the standard care group (TPE-) [1]. We would like to make some comments. The authors reported that the patients who received adjunct TPE had a more favorable fluid balance at $48 \mathrm{~h}$ [1]. TPE is not able to induce a negative fluid balance. Patients undergoing adjunct TPE required initiation of renal replacement therapy (RRT) in $67.6 \%$ of cases, compared to $51.4 \%$ in those receiving standard of care alone [1]. The mortality associated with the new need for RRT was $48 \%$ in those receiving TPE compared to $79 \%$ in those receiving standard of care alone [1]. Almost $70 \%$ of the TPE+ patients required RRT versus only $50 \%$ of the patients in the standard of care group [1]. One of the most impressive results seen was the greater relative reduction in mortality among patients receiving TPE who had a primary sepsis diagnosis of pneumonia (pneumonia 11/23 TPE+ [mortality 47.8\%] vs $15 / 17$ TPE- [mortality $88.2 \%$ ]), a situation

\footnotetext{
* Correspondence: Patrick.Honore@CHU-Brugmann.be

ICU Department, Centre Hospitalier Universitaire Brugmann-Brugmann

University Hospital, Place Van Gehuchtenplein, 4, 1020 Brussels, Belgium
}

where a negative fluid balance is so crucial [1]. Knowing that RRT is a very powerful tool to generate a negative fluid balance $[2,3]$, it is possible that the benefit in mortality could be linked to improved attainment of negative fluid balance in patients on RRT (70\% of the TPE group) $[1,4,5]$. Naturally, this is only a hypothesis and cannot be confirmed with the available data. Fluid balance data presented in the study suggest that there were significant differences at baseline that were not matched in the $\mathrm{TPE}+$ and TPE- groups [1]. Changes in fluid management over time, including the use of diuretics and $\mathrm{cu}$ mulative duration of RRT, were not reported [1]. Individualized treatment occurred in both groups based on physician preferences (e.g., adjunct steroids, ascorbic acid, thiamine), and this was also probably the case for RRT (70\% TPE+ vs 50\% TPE-) [1]. It appears that the "standard of care" varied considerably in the study. In conclusion, we wonder if the observed difference in mortality was a result of negative fluid balance due to RRT.

\section{Abbreviations}

TPE: Therapeutic plasma exchange; TPE+: Patient cohort receiving therapeutic plasma exchange; TPE-: Patient cohort receiving "standard of care"; RRT: Renal replacement therapy

\section{Acknowledgements \\ None.}




\section{Authors' contributions}

$\mathrm{PMH}, \mathrm{SR}$, and DDB designed the paper. All authors participated in drafting and reviewing. All authors read and approved the final version of the manuscript.

\section{Funding}

None.

Availability of data and materials

Not applicable.

\section{Ethics approval and consent to participate}

Not applicable.

\section{Consent for publication}

Not applicable.

\section{Competing interests}

The authors declare to have no competing interests.

Received: 29 August 2020 Accepted: 30 September 2020

Published online: 08 October 2020

\section{References}

1. Keith PD, Wells AH, Hodges J, Fast SH, Adams A, Scott LK. The therapeutic efficacy of adjunct therapeutic plasma exchange for septic shock with multiple organ failure: a single-center experience. Crit Care. 2020;24(1):518. https://doi.org/10.1186/s13054-020-03241-6.

2. Berthelsen RE, Perner A, Jensen AK, et al. Forced fluid removal in intensive care patients with acute kidney injury: the randomised FFAKI feasibility trial. Acta Anaesthesiol Scand. 2018;62(7):936-44. https://doi. org/10.1111/aas.13124.

3. Dos Santos TOC, Oliveira MAS, Monte JCM, et al. Outcomes from a cohort of patients with acute kidney injury subjected to continuous venovenous hemodiafiltration: the role of negative fluid balance. PLoS One. 2017;12(4): e0175897. https://doi.org/10.1371/journal.pone.0175897.

4. Boyd JH, Forbes J, Nakada TA, et al. Fluid resuscitation in septic shock: a positive fluid balance and elevated central venous pressure are associated with increased mortality. Crit Care Med. 2011;39(2):259-65. https://doi.org/ 10.1097/CCM.0b013e3181feeb15.

5. Acheampong A, Vincent JL. A positive fluid balance is an independent prognostic factor in patients with sepsis. Crit Care. 2015;19:251. https://doi. org/10.1186/s13054-015-0970-1.

\section{Publisher's Note}

Springer Nature remains neutral with regard to jurisdictional claims in published maps and institutional affiliations. 